\title{
Role of natural external forcing factors in modulating the Indian summer monsoon rainfall, the winter North Atlantic Oscillation and their relationship on inter-decadal timescale
}

\author{
Xuedong Cui $\cdot$ Yongqi Gao $\cdot$ Jianqi Sun $\cdot$ \\ Dong Guo • Shuanglin Li • Ola M. Johannessen
}

Received: 12 June 2013/ Accepted: 11 January 2014/Published online: 29 January 2014

(C) The Author(s) 2014. This article is published with open access at Springerlink.com

\begin{abstract}
We use reconstructed data and multi-centennial integrations performed with the Bergen Climate Model Version 2 to investigate the impact of natural external forcing factors on the Indian summer monsoon (ISM) rainfall, the winter North Atlantic Oscillation (NAO), and the potential relationship between the ISM rainfall and the winter NAO on decadal to inter-decadal timescales. The model simulations include a 600-year control integration (CTL600) and a 600-year integration with time-varied natural external forcing factors from 1400 to 1999 (EXT600). Both reconstructed data and the simulation showed increased ISM rainfall 2-3 years after strong volcanic eruptions. Strong volcanic eruptions decrease the Indian Ocean sea surface temperature (SST), which increases the strength of the southwesterly winds over the Arabian Sea. With negative externally-forced radiative anomaly, the lower stratospheric pole-to-equator winter
\end{abstract}

X. Cui · Y. Gao $(\bowtie)$ · J. Sun · S. Li · O. M. Johannessen

Nansen-Zhu International Research Centre, Institute

of Atmospheric Physics, Chinese Academy of Sciences,

PO Box 9804, Beijing 100029, China

e-mail: gyq@mail.iap.ac.cn

X. Cui

University of Chinese Academy of Sciences,

Beijing 100049, China

Y. Gao · O. M. Johannessen

Nansen Environmental and Remote Sensing Center,

Bergen, Norway

D. Guo $\cdot$ S. Li

Climate Change Research Center, Chinese Academy

of Sciences, Beijing 100029, China

O. M. Johannessen

Nansen Scientific Society, Bergen, Norway temperature gradient is enhanced, leading to a positive winter NAO anomaly with a time lag of 1 year. There is no significant correlation between the winter NAO and ISM rainfall in CTL600. However, the ISM rainfall is significantly positively correlated with the winter NAO in EXT600, with the NAO leading by $2-4$ years, which is consistent with the NAO-ISM rainfall relationship in the reconstructed data. We suggest that natural external forcing factors regulate the inter-decadal variability of both the winter NAO and the ISM rainfall and thus likely lead to an increased statistical but not causal relationship between them on the inter-decadal timescale over the past centuries.

Keywords Indian summer monsoon - North Atlantic Oscillation · External forcing factors · Inter-decadal timescale

\section{Introduction}

The most important climate feature in India is the Indian summer monsoon (ISM, also called South Asia summer monsoon) which occurs over the four summer months of June to September. It brings approximately $80 \%$ of the region's annual rainfall. The ISM plays a key role in Indian agriculture, and its anomaly often results in huge economic and societal consequences (Mooley et al. 1981; Mooley and Parthasarathy 1982).

External forcing factors like solar irradiance and volcanic eruptions can affect climate variability to a considerable extent (Free and Robock 1999; Crowley 2000; Shindell et al. 2001b). A number of studies have suggested that solar irradiance exerts a substantial influence on the low frequent variability of the ISM (e.g., Agnihotri et al. 2002; Wang et al. 2005; Fleitmann et al. 2003). Evidences 
show that stronger (weaker) solar forcing weakens (strengthens) the vertical temperature gradient in the tropics, leading to more (less) vigorous convection and thus increased (decreased) summer rainfall over India on decadal timescale (Kodera 2004; Bhattacharyya and Narasimha 2005). Lau et al. (2006) and Lau and Kim (2006) demonstrated that the absorption of solar radiation by aerosols heats up the elevated surface air over the slopes of the Tibet Plateau, which may increase ISM rainfall through the so-called "Elevated-Heat-Pump" effect. However, recent studies also show reduced ISM rainfall in response to "solar dimming" due to the direct and indirect effects of aerosols (e.g., Ramanathan et al. 2005; Meehl et al. 2008; Ganguly et al. 2012). Nonetheless, these imply the potential influence of volcanic eruptions on the ISM rainfall although the influence is not clear.

The North Atlantic Oscillation (NAO) presents one of the most prominent anomaly modes of inter-monthly to inter-decadal variability in the Northern Hemisphere winter and is characterized by a large-scale alternation of atmospheric mass with centers of action near the Icelandic low and the Azorian high (e.g., Wallace and Gutzler 1981; Hurrell 1995). Observations and model simulations have shown that external forcing factors like variations in solar activity and strong volcanic eruptions can modulate the NAO (e.g., Graf et al. 1993; Stenchikov et al. 2002; Shindell et al. 2003; Wang et al. 2012; Zanchettin et al. 2012). Climate simulations of the last millennium provide mixed results about NAO variability and its relation to natural external forcings. While Zanchettin et al. (2012) found a decadal NAO response to strong tropical volcanic eruptions in a single-model ensemble, Gómez-Navarro and Zorita (2013) did not find a significant imprint of natural external forcings on the inter-decadal NAO variability in a multi-model ensemble.

Previous studies suggested that, on both inter-annual and decadal timescales, the ISM is influenced by the NAO. On the inter-annual timescale, Chang et al. (2001) revealed the strong influence of Eurasian surface air temperature on the ISM rainfall over past several decades through strengthening of the positive phase of the NAO and the associated jet-stream/storm-track patterns over the North Atlantic and northern Eurasia. On decadal and inter-decadal timescales, Dugam et al. (1997) found that the winter and spring NAO had an inverse relationship with the ISM rainfall but they concluded that it is difficult to explain the long-term variability of ISM rainfall by only using the NAO signals. Goswami et al. (2006) proposed a physical mechanism for the linkage between the North Atlantic inter-decadal SST variations and the ISM through the winter NAO and the associated hemispheric change in winds, storm tracks, and tropospheric temperature anomalies. The strong negative (positive) NAO-related anomalies decrease (increase) the meridional gradient of the tropospheric temperature, resulting in below (above) normal ISM rainfall. The NAOISM relationship has been also found in paleoclimatic records (Singh et al. 2009; Fang et al. 2010). Li et al. (2008) found a similar linkage between the Atlantic multidecadal SST variability and the ISM rainfall, but they did not find an NAO-like atmospheric response. Therefore, the relationship between the NAO and the ISM rainfall on inter-decadal timescale is still under-debate. In view of the external forcing factors' (both volcanic eruptions and solar irradiance) impact on both ISM rainfall and NAO, we hypothesize that the natural external forcing factors can lead to the statistical relationship between the ISM rainfall and the NAO.

By using reconstructed data and the two multi-centennial integrations performed with the Bergen Climate Model (BCM; Otterå et al. 2009) Version 2, we found that strong volcanic eruptions can strengthen the ISM circulation and increase the ISM rainfall. Furthermore, the natural external forcing factors can regulate the relationship between the NAO and the ISM rainfall, which was seen in both the reconstructed data and the simulation. The remainder of this paper is organized as follows. A description of the BCM, the data sets and methods is presented in Sect. 2. In Sect. 3, we evaluate the inter-decadal variation of the simulated ISM rainfall and NAO, and explore their responses to natural external forcing factors as well as their relationship. Finally, discussions and conclusions are presented in Sect. 4.

\section{Descriptions of the BCM, datasets and methods}

The BCM is a fully coupled atmosphere-sea-ice-ocean general circulation model (GCM). The atmospheric component of the model is the spectral atmospheric GCM ARPEGE (Déqué et al. 1994), which was run with a truncation at wave number 63 (T63), a time step of 1,800 s, and a total of 31 vertical levels ranging from the surface to $0.01 \mathrm{hPa}$ (20 levels in the troposphere). The treatment of physics and the nonlinear terms in the model required spectral transformations to a Gaussian grid. The oceanic component of the BCM is the Miami Isopycnic Coordinate Ocean Model (MICOM) (Bleck et al. 1992). With the exception of the equatorial region, the ocean grid is almost regular with a horizontal grid spacing of approximately $2.4^{\circ} \times 2.4^{\circ}$. To better resolve the dynamics near the Equator, the horizontal spacing in the meridional direction is gradually decreased to $0.8^{\circ}$ at the Equator. MICOM has 34 vertical layers, with potential densities ranging from $1,029.514$ to $1,037.800 \mathrm{~kg} \mathrm{~m}^{-3}$ relative to a $2,000 \mathrm{~m}$ depth, and a non-isopycnic surface mixed layer on top providing the linkage between the atmospheric forcing and 
the ocean interior. The sea ice model is GELATO which was developed at METEO FRANCE and described in detail by Salas-Melia (2002). The OASIS (version 2) coupler was used to couple the atmosphere and ocean models. More details are provided by Otterå et al. (2009). The BCM is one of the climate models that were used for the 4th Assessment Report of the Intergovernmental Panel on Climate Change.

A total of seven simulations were included in this study. The CTL600 is a 600 year control simulation in which the natural external forcing factors had no year-to-year variations and greenhouse gas concentrations and tropospheric sulphate aerosols were fixed at pre-industrial (year 1850) levels. The EXT600 simulation includes external forcing factors due to variations in the total solar irradiance (TSI) and changes in the amount of stratospheric aerosols following explosive volcanic eruptions for the last 600 years. The other forcings were kept constant as in CTL600. The TSI forcing field is from Crowley et al. (2003). The remaining five runs cover the period 1850 to 1999 and were started with different initial conditions for the atmosphere. The ensemble mean of these runs is hereafter referred to as ALL150. In these runs, changes in tropospheric aerosols and well-mixed greenhouse gases were included in addition to natural external forcing factors. ALL150 ensemble simulations were used to investigate the relative importance of anthropogenic factors to associated climate changes compared to EXT600.

In order to study the impact of strong volcanic eruptions on the NAO and ISM rainfall, strong volcano events during the last 600 years are defined as the cases with a peak anomalous negative radiative forcing larger than $1 \mathrm{~W} \mathrm{~m}^{-2}$. Due to the fact that some volcano events occur close to the previous ones, seventeen strong volcanic eruptions are chosen here. These events occur in years 1453, 1460, 1586, 1600, 1620, 1641, 1674, 1680, 1693, 1809, 1815, 1831, $1883,1902,1963,1820$, and 1991. Please refer to Wang et al. (2012) for more details.

The other data used in this study include the Hadley Centre monthly sea level pressure (SLP) from 1850 to 2004, gridded at $5^{\circ} \times 5^{\circ}$ resolution (HadSLP2; Allan and Ansell 2006), monthly winds at 850 and $200 \mathrm{hPa}$ from the National Centers for Environmental Prediction-National Center for Atmospheric Research (NCEP-NCAR) reanalysis (Kalnay et al. 1996), and three reconstructed NAO indices: (1) Cook et al. (2002) for 1400-1999, hereafter Cook-NAO; (2) Luterbacher et al. (2002) for 1500-1999, hereafter Luterb-NAO; and (3) Trouet et al. (2009) for 1400-1995, hereafter Trouet-NAO. In addition, the reconstructed Monsoon Asia Drought Atlas (MADA) over the last millennium (Cook et al. 2010) was used. The MADA provided a resolved gridded spatial reconstruction of seasonalized Palmer Drought Severity Index (PDSI) for the summer monsoon season, derived from a network of tree-ring chronologies.

Because we focus on the decadal to inter-decadal variability in the ISM rainfall and the winter NAO, prior to analysis, the time series of all the climate variables are 10-year low-pass filtered using a first-order Butterworth filter (Butterworth 1930) unless otherwise specified. Linear regressions and correlations are used. The statistical significance of the correlation and regression coefficients was estimated by the Monte Carlo technique (Hope 1968). Two standard time series are generated randomly and filtered to obtain low-pass indices by a Butterworth filter, which produces a correlation coefficient. Then we repeat the above process for 10,000 times and rank the coefficients in ascending order to determine the 95 and $99 \%$ spread of the coefficients.

\section{Results}

3.1 The simulated inter-decadal variation of ISM and its response to natural external forcing factors

\subsubsection{The simulated ISM}

The ISM index defined by Lau et al. (2000) is often used to describe the Indian summer rainfall, which is closely related with the cross equatorial atmospheric flow (Ramesh Kumar et al. 1999). The Lau et al. (2000) index is calculated as the meridional wind shear (V850 minus V200) averaged over the region $\left(10^{\circ} \mathrm{N}-30^{\circ} \mathrm{N}, 70^{\circ} \mathrm{E}-110^{\circ} \mathrm{E}\right)$, where V850 and V200 is the meridional wind speed $(\mathrm{m} / \mathrm{s})$ at 850 and $200 \mathrm{hPa}$, respectively. The decadal variability of the ISM in CTL600 and EXT600 explains 26.2 and $18.5 \%$ of the total variance, respectively. The CTL600 and EXT600 can well reproduce the regression distribution between the ISM index and the observed rainfall as shown in figure 5 of Lau et al. (2000). Figure 1 indicates that the model can reproduce the observed seasonality of the ISM with the simulated onset of the ISM delayed by 1 month, and that the natural external forcing factors did not lead to significant changes (by student's $t$ test) in the simulated seasonality of the ISM over the past 600 years. Luo et al. (2011), using the monsoon index defined by the Indian rainfall, also found a 1 month postponement of the ISM onset in CTL600. They suggested that the simulated delay of ISM onset is due to the weakened land-ocean pressure gradient over the western side of the Indian Ocean and the weakened Somali low-level jet in June compared to observations. Their results also indicated that both the simulated atmospheric circulation in the lower troposphere (both in CTL600 and ALL150) and the summer rainfall over South Asia are similar to observations. The 
simulations (CTL600, EXT600, ALL150) reproduce the strong rainfall in the west of India, the Bay of Bengal and the southwest of Indochina Peninsula, respectively. The difference in the simulated summer precipitation climatology $\left(0^{\circ}-30^{\circ} \mathrm{N}, 70^{\circ} \mathrm{E}-110^{\circ} \mathrm{E}\right)$ between CTL600 and EXT600 is less than $3 \%$ of that in CTL600, indicating that natural external forcing factors did not significantly affect the annually averaged summer rainfall in the south Asian monsoon region over the past 600 years.

\subsubsection{Response of the ISM rainfall to natural external forcing factors}

A total external forcing index (TEFI) is used to represent the anomaly in total short-wave radiation flux caused by changing solar irradiance and by volcanic eruptions (Otterå et al. 2010). The TEFI is the sum of solar irradiance anomaly and radiative forcing which is converted from the volcanic aerosol loading values by dividing by 30 and multiplying by 23.5. The decadal variability of the TEFI explains $51.7 \%$ of the total variance. The simulated ISM rainfall (represented by the ISM index) in EXT600 is negatively correlated with the TEFI $(\mathrm{r}=-039, P<0.01)$ when the TEFI leads by $3-5$ years (Fig. 2). However, there is a negative, but non-significant, correlation between the simulated ISM rainfall and the applied TSI forcing $(\mathrm{r}=-$ 0.12 ; the TSI leading by $2-3$ years; not shown). This suggests a potential role for volcanic eruptions in regulating the decadal and inter-decadal variations of ISM rainfall. To further test the volcanic impact on the ISM rainfall, we performed a superposed epoch analysis (SEA; Haurwitz and Brier 1981) similar to Zanchettin et al. (2012) to examine the behavior of the ISM rainfall before, during, and after strong volcanic eruptions. Figure 3 a shows the change of unfiltered ISM index in EXT600 before and after volcanic eruptions. A significant positive response in the ISM index is seen in 2-3 years after the strong volcanic events. Correspondingly, there are positive anomalies in summer rainfall in the 3rd post-eruption year, with a

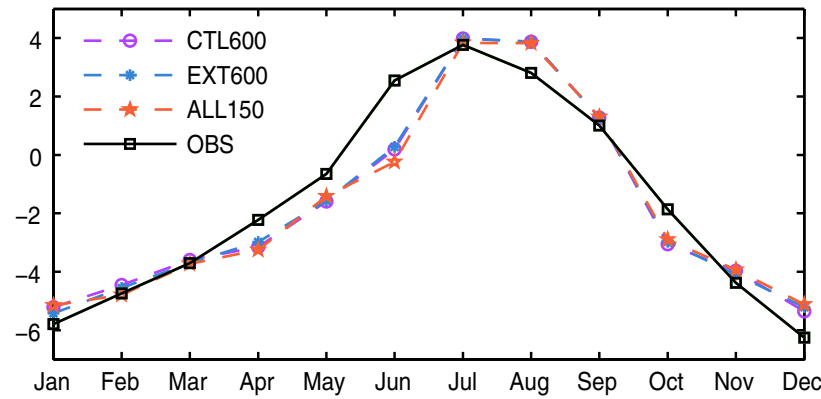

Fig. 1 Seasonal evolution of the ISM index. Dashed lines are simulated index for CTL600 (Purple), EXT600 (blue), ALL150 (red) and solid line is observed index (black). Unit: $\mathrm{m} / \mathrm{s}$ maximum value of $0.9 \mathrm{~mm} /$ day (about $12 \%$ increase of the averaged summer rainfall) in central India (Fig. 3b). Furthermore, the spatial pattern of the simulated summer rainfall anomalies is consistent with that from the reconstructed data (Fig. 3c). In brief, both the reconstructed data and the simulation show the increased ISM rainfall $2-3$ years after the volcanic eruptions.

To explore how the natural external forcing factors influence the ISM rainfall, we examine the atmospheric and oceanic responses to the natural external forcing factors. A significant positive correlation is found between the TEFI and tropical Indian Ocean summer (July, August, September) SST (Fig. 4a). The timeseries of TEFI and TSI are found to be highly correlated $(r=0.83$ for TEFI and $\mathrm{r}=0.49$ for TSI, $P<0.01$ ) with the time series of the tropical Indian Ocean $\left(24^{\circ} \mathrm{S}-24^{\circ} \mathrm{N}, 40^{\circ} \mathrm{E}-120^{\circ} \mathrm{E}\right)$ summer SST when the TEFI and TSI lead the SST by 3 years. The 3-year time lag can be explained by the radiation balance between solar insolation and long-wave back radiation anomalies as suggested by White et al. (1997): The change in SST will take about 3-year before the ocean long-wave back radiation is in balance with the changed solar insolation. Furthermore, the significant cooling in the tropical ocean, occurring approximately 3 years after volcanic eruptions, was reported by D'Arrigo et al. (2008). Zanchettin et al. (2013a) also suggested that strong volcanic eruptions could impact on the tropical Indian Ocean SSTs on decadal timescale during the last millennium. Previous studies have indicated that tropical summer SST anomalies (SSTA) are closely related to the ISM rainfall on interannual and inter-decadal timescales. The inter-annual variation of the ISM rainfall is negatively correlated with the Indian Ocean and the eastern Pacific SSTA (Lau et al. 2000), which is consistent with our model results. Krishnamurthy and Goswami (2000) indicated that on interdecadal timescale there is a statistically significant, negative correlation between the tropical Indian Ocean SST and

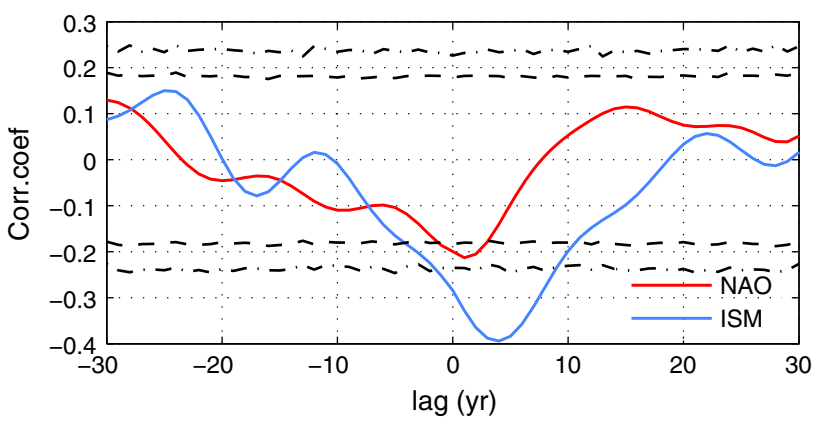

Fig. 2 Lead-lag correlation coefficients between the external forcing index (TEFI) and the winter NAO (red), between the TEFI and the ISM (blue) in EXT600, positive lag means the TEFI is leading. Solid curves denote correlation coefficients, dashed (dot-dashed) lines indicate the $95 \%$ (99\%) levels of significance 
Fig. 3 a Superposed epoch analysis of simulated posteruption evolution of the unfiltered ISM index. Vertical solid line indicates the timing of occurrence of the eruption, values prior to the eruption are shown as a scatter plot, while post-eruption values are shown as a continuous curve. Dashed lines indicate $95 \%$ levels of significance derived from 10,000 Monte Carlo realizations. b The composite anomalies of simulated unfiltered summer precipitation (unit: $\mathrm{mm} /$ day) in the 3 rd year after eruption. The grid points marked by black dots indicate significance at the $95 \%$ level. c As in $\mathbf{b}$, but for the composite anomalies of the summer unfiltered PDSI from MADA. In a-c, the climatology during the eight pre-eruption years is used as the reference period
Fig. 4 a Regression pattern between the low-frequency tropical Indian Ocean summer (JAS) SST and the TEFI in EXT600, with temperature lagging the TEFI by 3 years. Areas with correlation coefficients significant at the $95 \%$ confidence level are shaded. Values are scaled to correspond to one standard deviation of TEFI. Unit: ${ }^{\circ} \mathrm{C}$. b Time series of the lowfrequency external forcing index (red), TSI (blue) and tropical Indian SST index (black) in EXT600
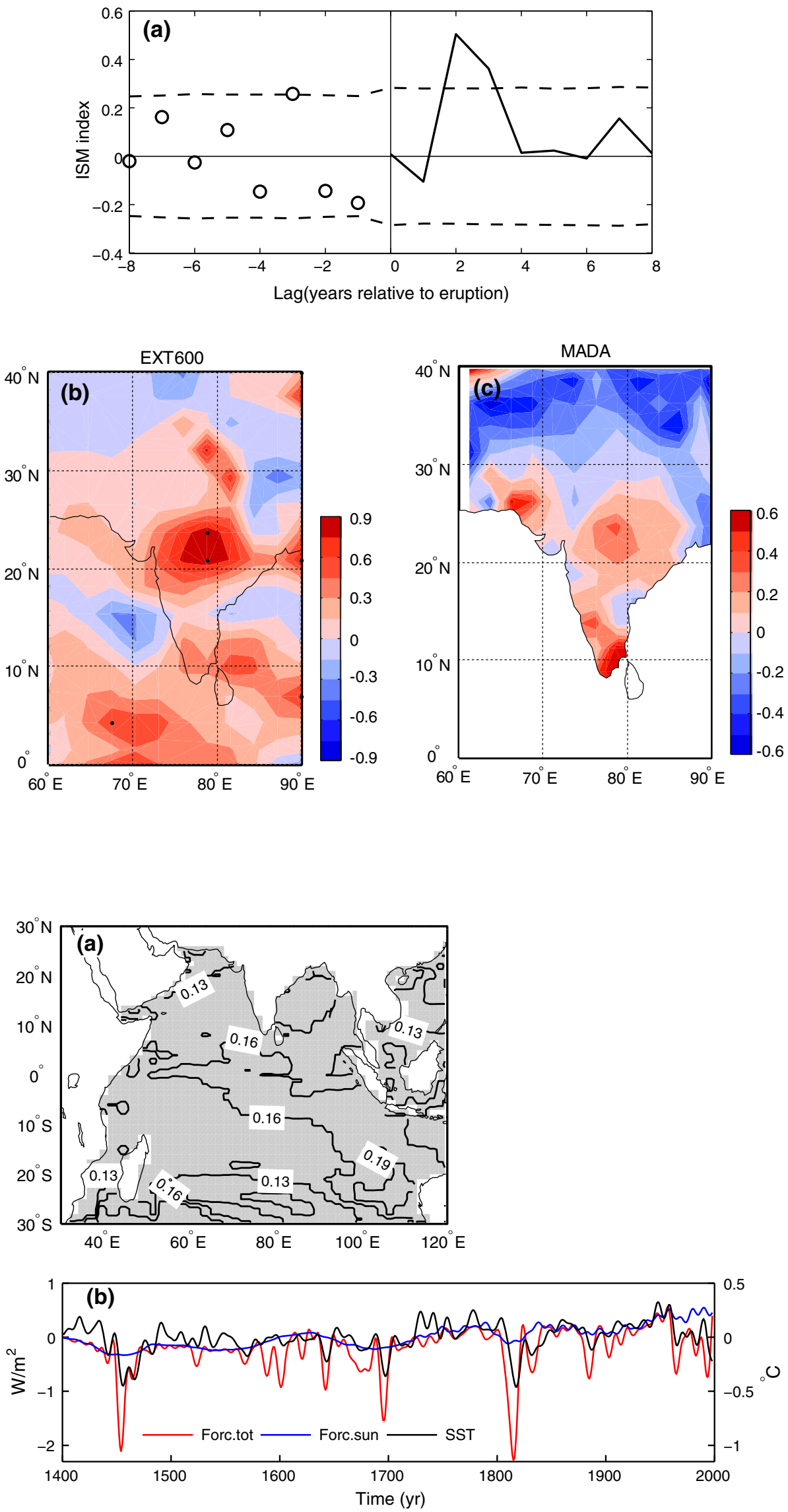

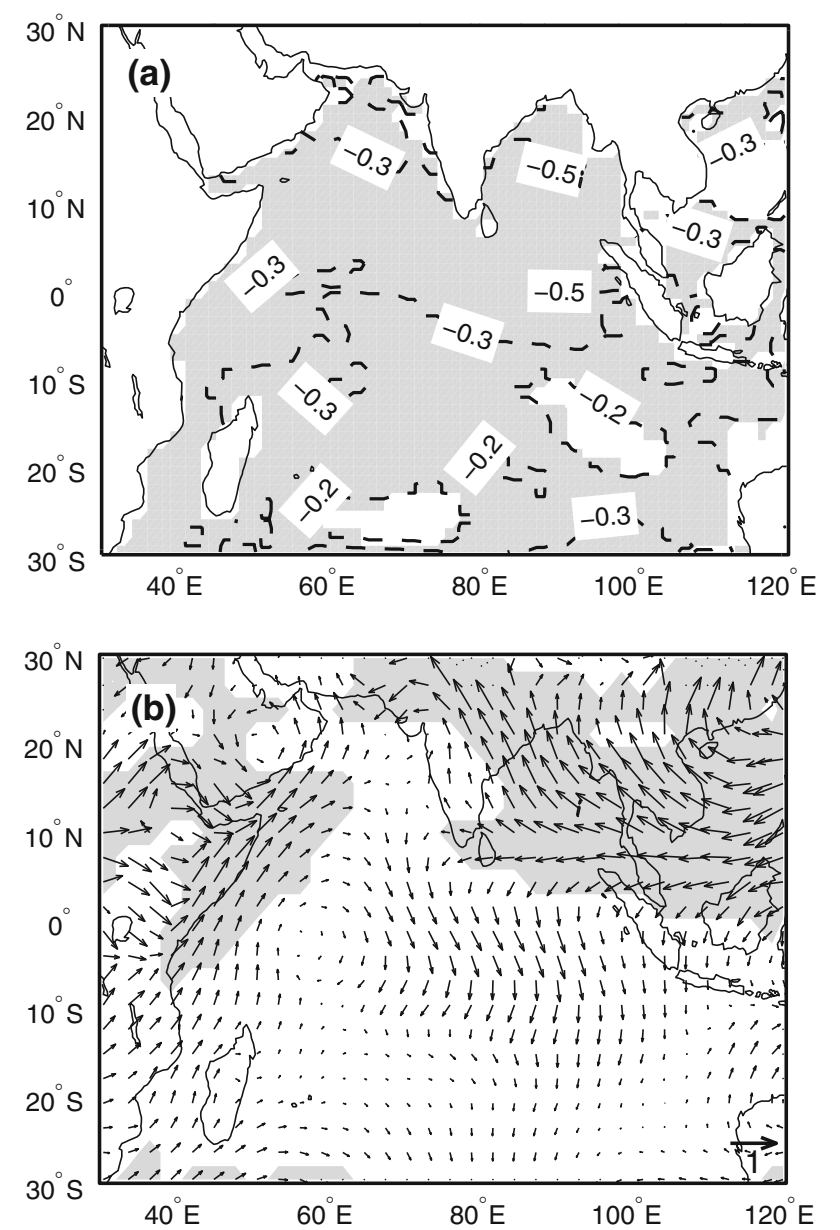

Fig. 5 a Simultaneous correlations between the ISM index and the low-frequency summer (JAS) SST anomalies in EXT600. b Simultaneous correlation between the ISM index and the low-frequency summer (JAS) $850 \mathrm{hPa}$ wind in EXT600. Areas with correlation coefficients significant at the $95 \%$ confidence level are shaded

the ISM rainfall anomalies. Figure 5 shows the correlation between the time series of the ISM index in EXT600 and the Indian Ocean SST (Fig. 5a) and $850 \mathrm{hPa}$ wind field (Fig. 5b). We find that higher ISM index is connected with decreased SST in the Indian Ocean and increased southwesterly over the Arabian Sea and with southeasterly flow from the Pacific warm pool to Indian continent. Kucharski et al. (2006) suggested that the local Indian Ocean SST forcing contributes considerably to decadal ISM rainfall variations and proposed the mechanism, which is also present in our model, that the cold (warm) tropical Indian Ocean can cause a low-level anticyclone (cyclone) with associated divergence (convergence), which modifies the local Hadley circulation and strengthens (weakens) the ISM circulation. Indeed, Fig. 5b clearly shows the anticyclone anomaly associated with a low-level divergence between $10^{\circ} \mathrm{S}$ and $15^{\circ} \mathrm{N}$ (only significant in its western branch) and a low-level convergence over the Indian continent $\left(15^{\circ} \mathrm{N}-25^{\circ} \mathrm{N}\right)$. The anomalous ascending motion over the Indian continent and the southwesterly anomalies induced water vapor transportation increase the ISM rainfall (figure not shown). Our results show that the natural external forcing factors, particularly the volcanic eruptions, can influence the ISM rainfall potentially through the modulation of the tropical Indian Ocean SST.

3.2 The simulated inter-decadal variation of NAO and its response to natural external forcing factors

\subsubsection{The simulated $N A O$}

The NAO here is defined as the leading Empirical Orthogonal Function (EOF) of SLP anomalies over the Atlantic sector $\left(20^{\circ}-80^{\circ} \mathrm{N}, 90^{\circ} \mathrm{W}-40^{\circ} \mathrm{E}\right.$; Hurrell 1995). The decadal variability of the NAO in CTL600 and EXT600 explain 22.2 and $18.8 \%$ of the total variance, respectively. The simulations (EXT600, ALL150) capture the winter NAO SLP dipole anomalies between the Arctic and the mid-latitude with a boundary at approximately $55^{\circ} \mathrm{N}$ (Fig. 6). The spatial correlation coefficients are 0.91 between EXT600 and HadSLP2 and 0.92 between ALL150 and HadSLP2. Negative SLP anomalies are present over the Arctic and high latitude regions, whereas positive anomaly centers are evident over the Atlantic Ocean. The first EOF mode of the North Atlantic SLP explains $47.6 \%$ of the variance in EXT600 for the period 1400 to 1999 , $49.5 \%$ in ALL150 and $46.7 \%$ in the HadSLP2 data for the past 150 years. The main discrepancies between the model (both EXT600 and ALL600) and the observations are: (1) the simulated negative SLP anomalies over North American expand further south, (2) the simulated positive center over the North Atlantic is stronger, and (3) the observed high pressure anomaly is located over the western European continent and the eastern North Atlantic Ocean, but the simulated centers are shifted westward. In addition, the spatial pattern of the SLP anomalies in CTL600 is essentially identical to that in EXT600 with a spatial correlation coefficient of 0.99 (figure not shown), indicating that natural external forcing factors did not cause a significant change in the locations of NAO action centers over the past 600 years.

In order to evaluate the variability of the simulated NAO on inter-decadal timescale, three reconstructed NAO indices are used. To exclude the effect of greenhouse gases, the reconstructed NAO before the year 1850 is used to assess the simulated NAO in EXT600. The simulated NAO in EXT600 shows more similarities with the Cook-NAO than that in CTL600, and larger correlation coefficient with the Cook-NAO (Fig. 6d). These results suggest that external forcing factors, such as solar irradiance and/or volcanic eruptions, may impact the variation of the NAO. However, the correlations between the simulated NAO and the 
(a) EXT600 47.6\%

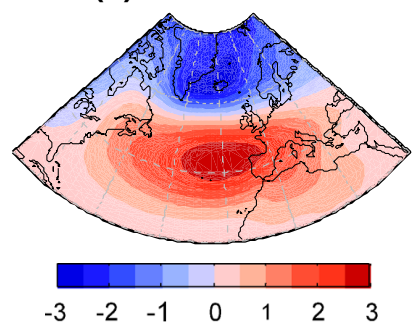

(b) ALL150 49.5\%

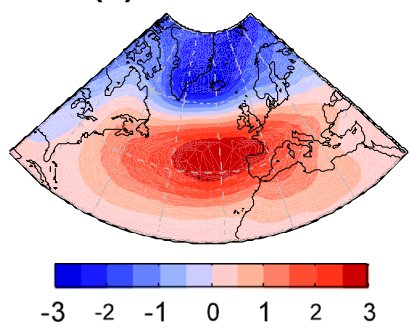

(c) $\operatorname{HadSLP2} 46.7 \%$

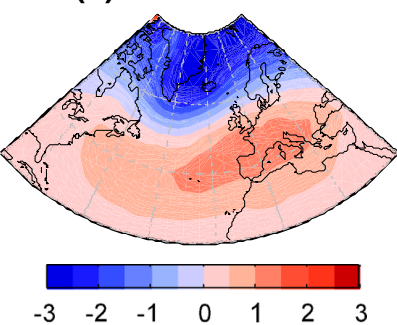

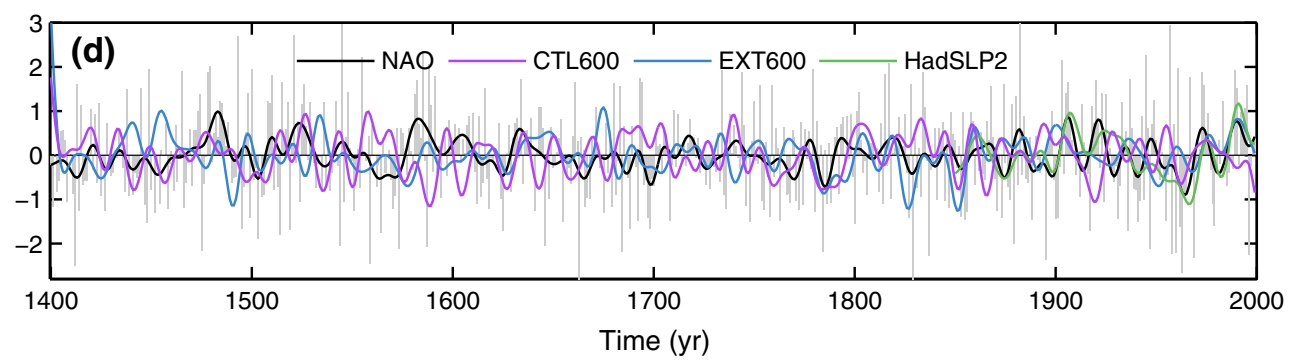

Fig. 6 The simulated and observed NAO patterns and indices. a Regressions of the North Atlantic SLP (unit: hPa) onto the NAO index in EXT600 for the past 600 years, b the same as a, but for ALL150 for the past 150 years and $\mathbf{c}$ the same as a, but for HadSLP2 for the past 150 years. Values are scaled to correspond to one standard deviation of NAO. d NAO index for the past 600 years for CTL600 (purple), the past 600 years for EXT600 (blue), the past 150 years for HadSLP2 (green) and the reconstructed NAO index (black). The grey bars are the unfiltered NAO index; other time series are filtered with a cut-off frequency equivalent to 10 years
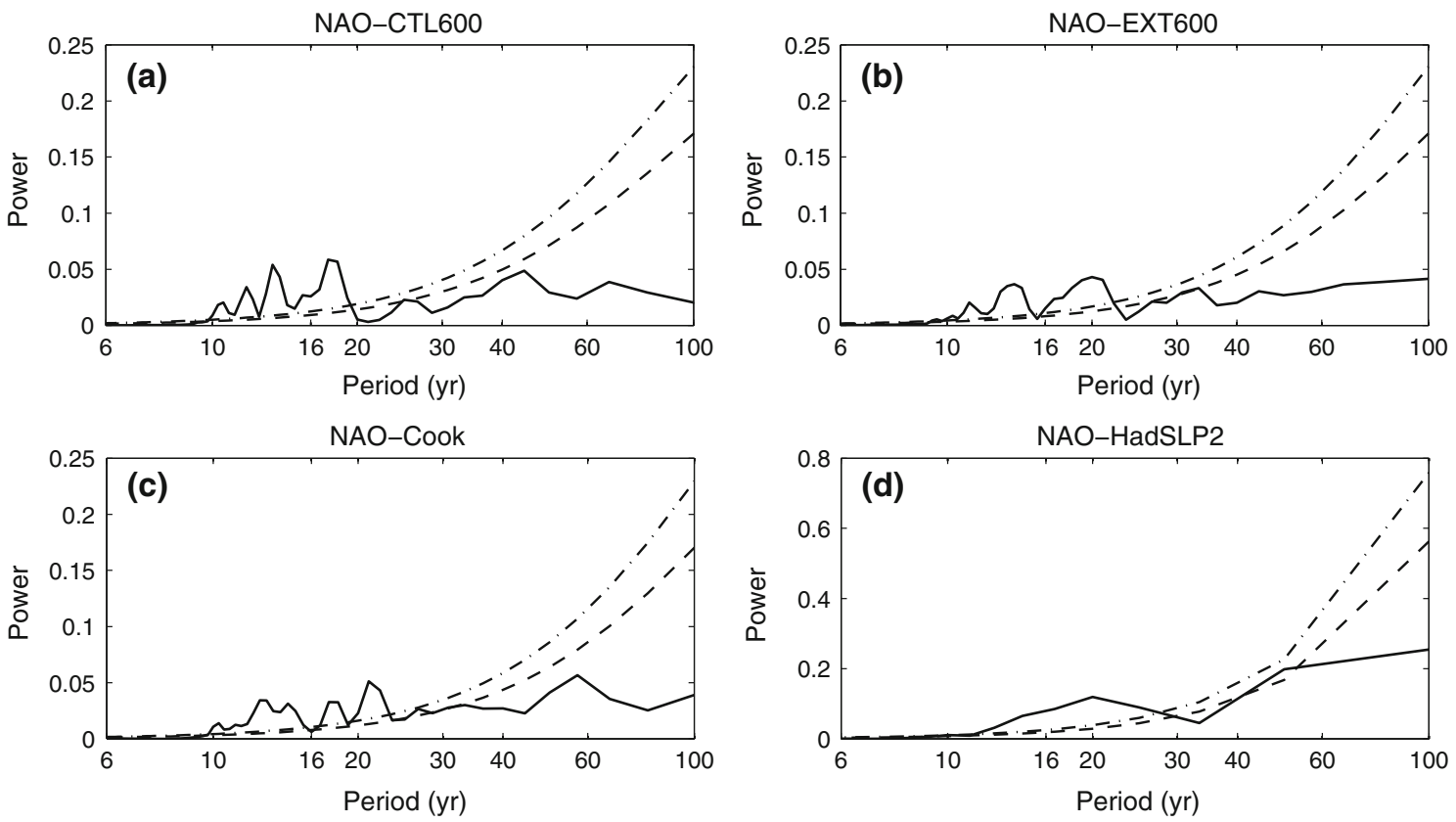

Fig. 7 The power spectrum of the filtered winter a NAO for CTL600, b NAO for EXT600, c Cook-NAO, d NAO for HadSLP2. Solid curves denote spectral power, dashed (dot-dashed) lines indicate the $95 \%(99 \%)$ level of significance

reconstructed one are low. This may be related to the representativeness of the reconstructed indices. Lehner et al. (2012) suggested that proxy locations that were used in the reconstruction are not always sufficient to describe the NAO. It should be mentioned that the correlation between the observed NAO and the Cook-NAO $(r=0.73)$ is highest compared with other reconstructed indices. Figure 7 shows the periodicities of the observed NAO, the 
(a) EXT600

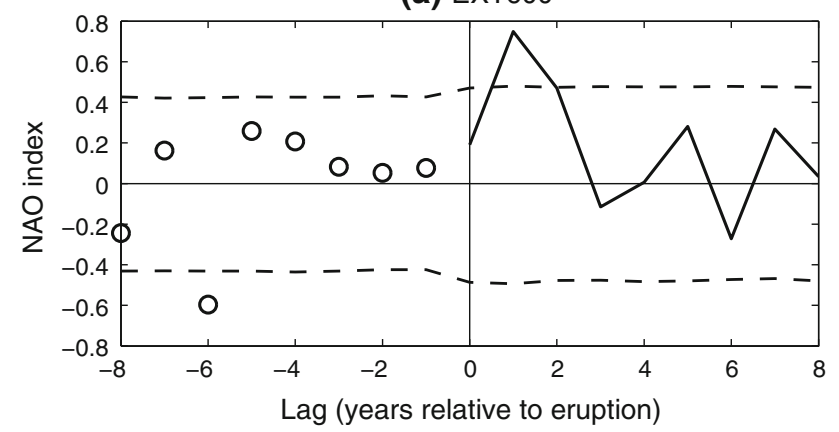

(b) Cook

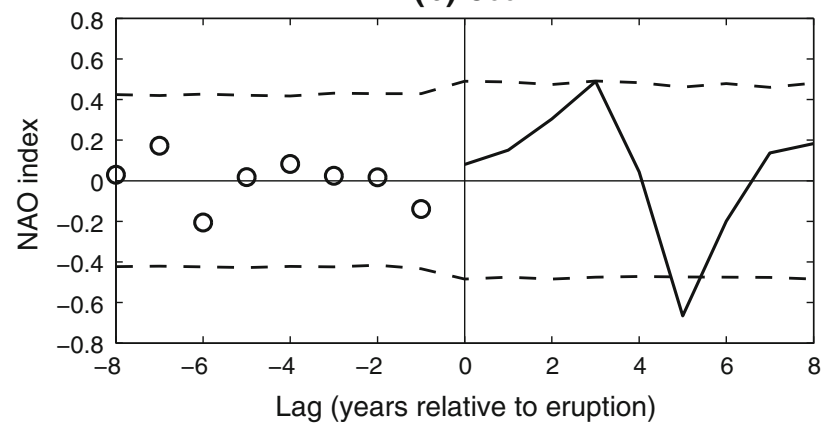

(c) Luterbacher

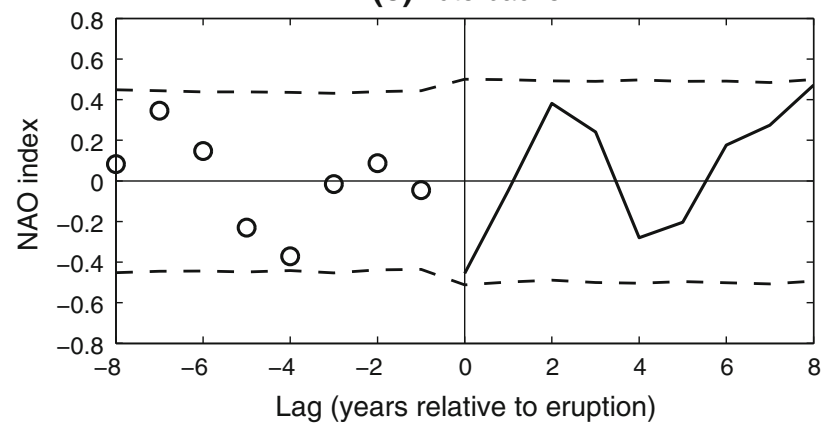

Fig. 8 Superposed epoch analysis of post-eruption evolution of a the simulated unfiltered NAO index for EXT600, b the unfiltered CookNAO index and $\mathbf{c}$ the unfiltered Luterb-NAO index. Vertical solid line indicates the timing of occurrence of the eruption, values prior to the eruption are shown as a scatter plot, while post-eruption values are shown as a continuous curve. Dashed lines indicate $95 \%$ level of significance derived from 10,000 Monte Carlo simulations

Cook-NAO, and the modeled winter NAO in both CTL600 and EXT600. The power spectrum analysis indicated that the NAO in EXT600 and the Cook-NAO have the same dominant periodicities of approximately 11-14 and 22 years (Fig. 7b, c), and that the observed winter NAO shows a peak periodicity of approximately 22 years (Fig. 7d). These two cycles (11-14 and 22 years) in the Cook-NAO (also in Luterb-NAO, figure not shown) and the simulated NAO are similar to the periodicities of TSI in our model. This is consistent with Howard and Labonte (1980) and Mursula et al. (2001), and likely indicates a modulation of solar irradiance on the periodicities of the
NAO. It should be mentioned that the period of about 22 years is also present in the simulated (EXT600), reconstructed (Cook-NAO and Luterb-NAO; Note the Trouet NAO is 30-year smoothed) and observed NAO before we do the 10-year filtering (figure not show). The period of about 16 years is strongest in CTL600, but also is present in EXT600 and reconstructed NAO, illustrating the intrinsic origin of the NAO variability. The power spectral analysis indicates that the NAO in EXT600 has more similar spectral features to the reconstructed NAO that the NAO in CTL600 and this increased similarity may be attributed to an excitement of certain frequencies by natural external forcing factors.

\subsubsection{Response of the NAO to natural external forcing factors}

Previous studies have suggested lagged relationships between low-frequency TSI and the NAO through atmospheric teleconnections from the Pacific Ocean (Swingedouw et al. 2011) as well as stratosphere-troposphere coupling (Shindell et al. 2001a). The most significant correlation in EXT600 occurs when the TEFI leads the NAO by 1 year (Fig. 2). However, there is no significant correlation between the simulated NAO in EXT600 and the applied TSI forcing when TSI leads the NAO by 1 year, suggesting a potential role of volcanic eruptions in modulating the NAO in our model. The large volcanic eruptions have a tendency to induce a positive NAO response (Otterå et al. 2010; Wang et al. 2012; Zanchettin et al. 2012).

We performed a SEA on the simulated and reconstructed unfiltered NAO to study the impact of strong volcanic eruptions on the NAO. Based on Zanchettin et al. (2012), the Northern Hemisphere atmospheric anomalies caused by the strong volcanic eruptions could last for 20 years. Thus, the eruptions in the years 1460, 1680, and 1809 are excluded here. Figure 8a shows the results of SEA on the simulated NAO in EXT600 during last 600 years. The NAO index increases significantly during the second year following the strong volcanic eruptions. For the reconstructed NAO indices (Fig. 8b, c), a positive trend of the NAO is found 2-3 years after the selected strong volcanic events. Note that the Luterb-NAO tends towards positive anomalies after the eighth post-eruption year, which is consistent with Zanchettin et al. (2013b), indicating a significant positive NAO anomaly develops after the eruption and persists throughout the first poseeruption decade. It is known from both observational and modeling studies that volcanic eruptions induce aerosol radiative heating in the lower stratosphere, leading to warming in the tropics and thus to a stronger meridional temperature gradient, which is associated with a stronger polar vortex (Graf et al. 1993; Stenchikov et al. 2002; 

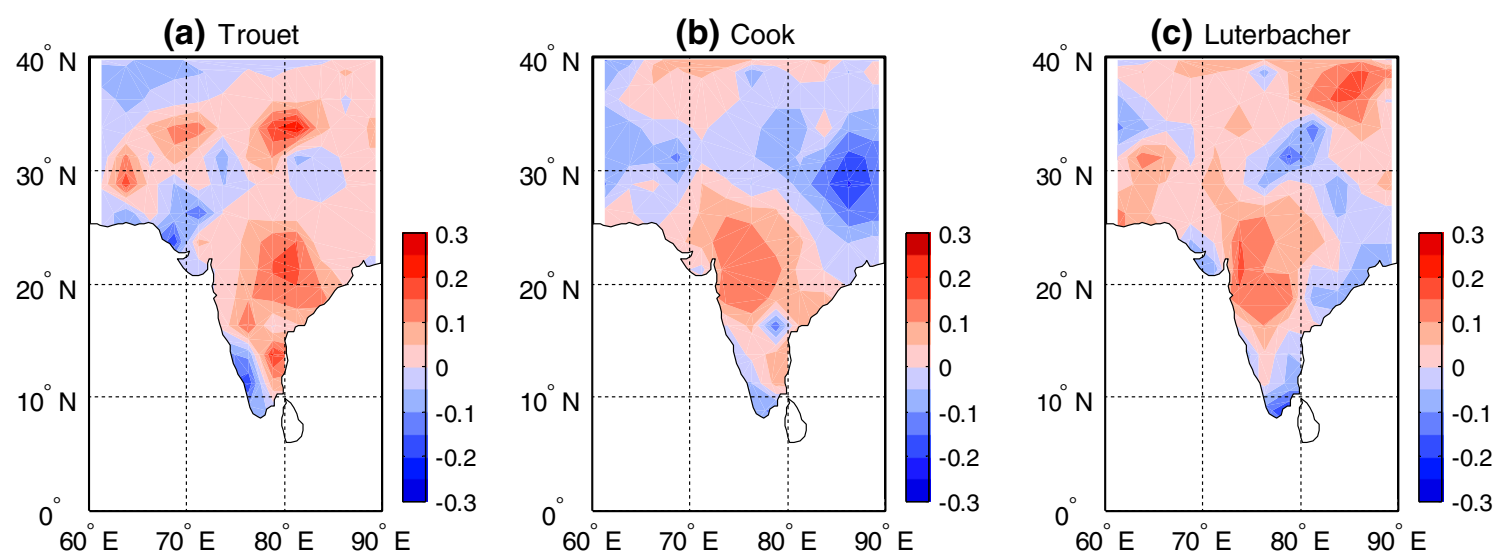

Fig. 9 Correlations between the three reconstructed NAO and the June-July-August PDSI from MADA, with the PDSI lagging the NAO by 2-4 years. a NAO from Trouet et al. (2009), b NAO from Cook et al. (2002), c NAO from Luterbacher et al. (2002)

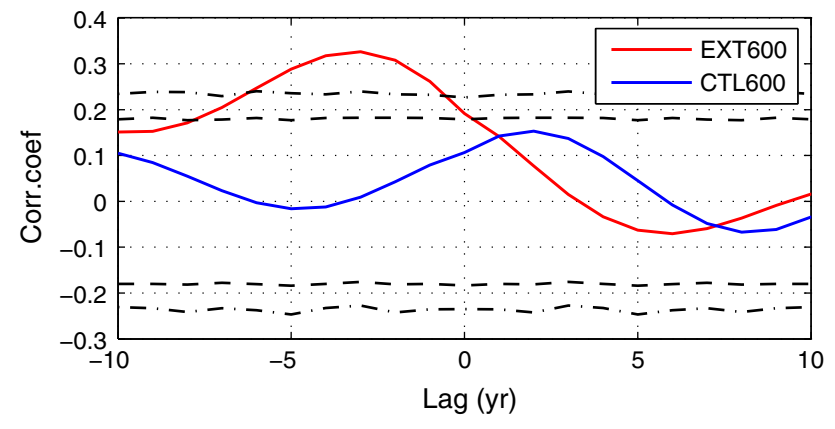

Fig. 10 Lead-lag correlation coefficients between the winter NAO and the ISM in CTL600 (red) and EXT600 (blue). Negative lag means that the NAO is leading. Dashed (dot-dashed) lines indicate the $95 \%(99 \%)$ levels of significance

Shindell et al. 2003; Wang et al. 2012; Zanchettin et al.

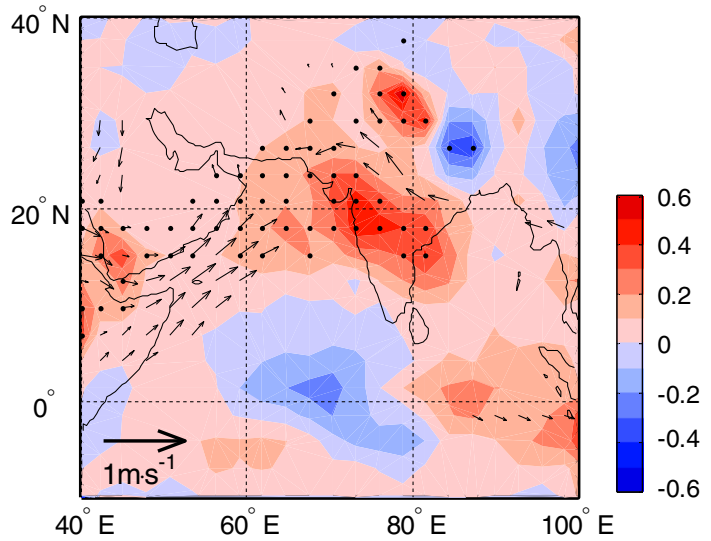

Fig. 11 Regressions of the 10-year low-pass filtered summer (JAS) precipitation (unit: $\mathrm{mm} /$ day) and $850 \mathrm{hPa}$ horizontal wind (unit: $\mathrm{m} / \mathrm{s}$ ) onto the winter NAO in EXT600, with precipitation and wind lagging the NAO by 3 years. For the precipitation, the grid points marked by black dots indicate significance at the $95 \%$ level. For the wind, only regions significant at the $95 \%$ level are shown. Values are scaled to correspond to one standard deviation of NAO
2012). Our study also shows that the NAO shifts to positive phase in response to negative TEFI anomaly due to a stronger meridional temperature gradient through a similar mechanism (figure not shown).

\subsection{NAO-ISM relation}

\subsubsection{NAO-ISM rainfall from reconstructed data}

Previous studies have suggested either an inverse or a positive relationship between the winter NAO and the ISM rainfall on inter-decadal timescale (Dugam et al. 1997; Goswami et al. 2006). We performed correlation analysis between the datasets of reconstructed NAOs and the summer PDSI from the MADA during 1400 to 1850. The results show that there is a wet (dry) condition in the Indian subcontinent following a positive (negative) phase of NAO (Fig. 9). The consistent correlation patterns between the three datasets of reconstructed NAO and the PDSI/MADA support the idea of a potential positive relationship between the NAO and the ISM rainfall with the NAO leading the PDSI by $2-4$ years, though the correlation in our analysis is not significantly at $95 \%$ confidence level.

\subsubsection{NAO-ISM rainfall relation from simulations}

There is a statistically significant correlation $(\mathrm{r}=0.33)$ between the winter NAO and the ISM rainfall in EXT600 when the NAO leads the ISM rainfall by $2-4$ years. Since there is no similar statistically significant correlation in CTL600 (Fig. 10), the natural external forcing factors are potentially the reason for the positive correlation between winter NAO and ISM rainfall in EXT600. The spatial distribution of the summer precipitation anomalies (i.e. the regression coefficients), corresponding to one-standarddeviation of positive winter NAO index, exhibits a tri-pole 

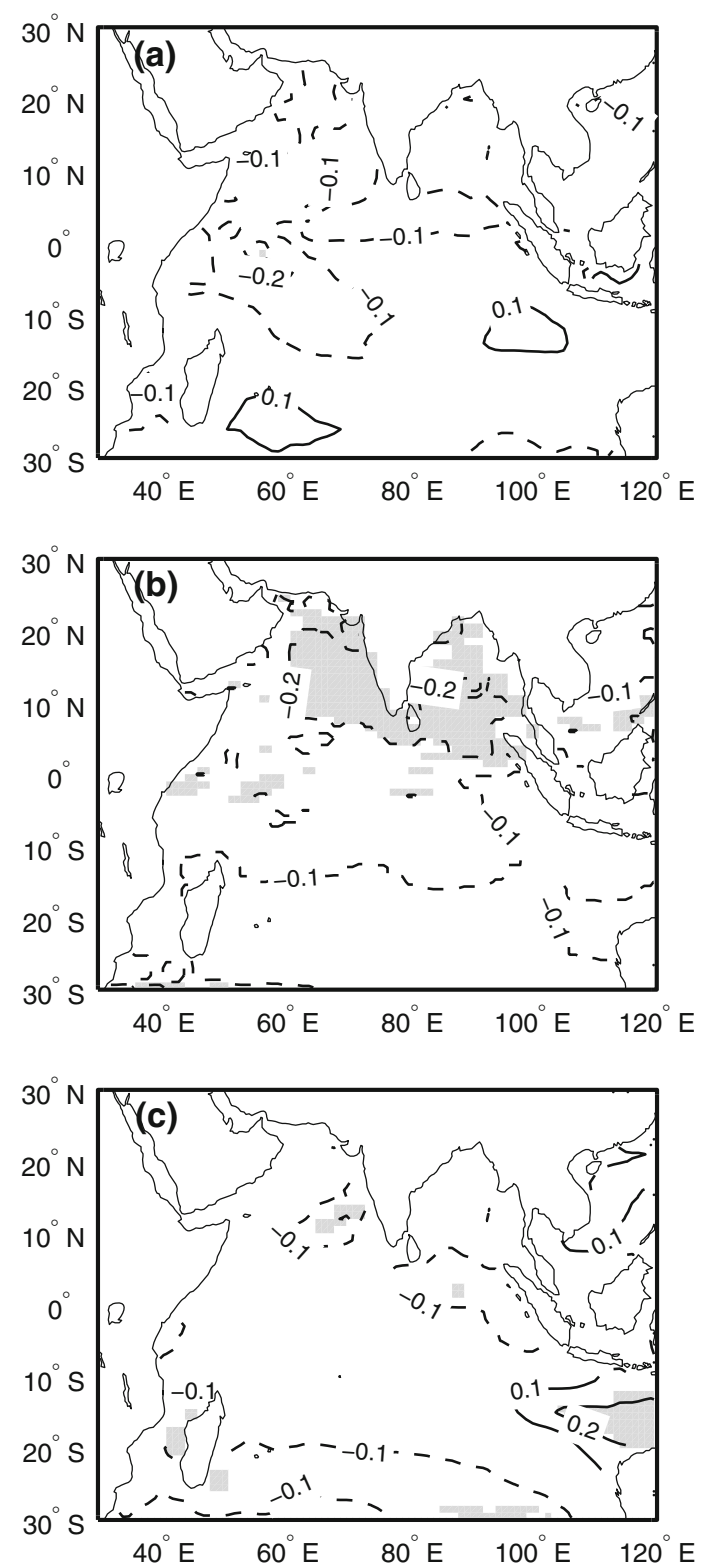

Fig. 12 Correlations between the winter NAO and the 10-year lowpass filtered summer (JAS) SST anomalies in CTL600 (a) and EXT600 (b), with temperatures lagging the NAO by 3 years. c Same as for Fig. 11b but removed the TEFI signals in the variables of the NAO and SST anomalies. Areas with correlation coefficients significant at the $95 \%$ confidence level are shaded

pattern with positive rainfall anomalies in the Indian subcontinent and the equatorial Indian Ocean and negative anomalies in-between (Fig. 11). The tri-pole distribution of rainfall anomalies is consistent with that shown in Lau et al. (2000) and is related to the Asian "southwest" monsoon wind over the Arabian Sea (Fig. 11). This stronger low-level flow carries more water vapor from the ocean (figure not shown) and leads to more rainfall in the Indian subcontinent, which was also suggested by Ramesh
Kumar et al. (1999). As illustrated before, the TEFI is significantly negatively correlated with the winter NAO and the ISM rainfall, with the TEFI leading the NAO and the ISM rainfall by 1 year and 3-5 years, respectively.

The negative correlation between the NAO and the Indian Ocean SST is significant in EXT600 compared with that in CTL600 (Fig. 12a, b). In EXT600, the winter NAO is significantly correlated with the summer SST over the Arabian Sea and the Bay of Bengal, where the SST anomalies have an inverse relationship with the ISM rainfall on inter-annual and inter-decadal timescales (e.g., Shukla 1975; Weare 1979; Kucharski et al. 2006). To further verify the natural external forcing factors' effect, we remove the TEFI signals from the NAO and the Indian Ocean SST in EXT600 by means of regression analysis which was also used by Gong et al. (2011). We found that the correlation pattern between the NAO and the Indian Ocean SST after the removal of the TEFI signal (Fig. 12c) is similar to the pattern in CTL600 (Fig. 12a), implying the significant correlation between the winter NAO and the Indian Ocean SST is likely caused by natural external forcing factors. We suggest the relationship between the winter NAO and ISM rainfall is of statistical nature and is not causation. This is due to both the NAO and the Indian Ocean summer SST reacting to the imposed forcings and especially to episodic volcanic events. With negative externally-forced radiative anomaly, volcanic aerosols are injected into the stratosphere, which scatter back to space the incoming shortwave radiation and also absorb the solar near-infrared and terrestrial radiation (Stenchikov et al. 1998; Ramachandran et al. 2000). On one hand, the stratospheric heating is greater in the low-latitude. As a result, the pole-to-equator winter temperature gradient increases, which leads to a positive winter NAO anomaly. On the other hand, the tropical Indian Ocean SSTs start to decrease due to reduced shortwave radiation. The cooling will last for approximately 3 years. These SST anomalies are also evident in the summer and contribute significantly to inter-decadal ISM variability. Therefore, the natural external forcing factors generate a statistical correlation between the NAO and ISM rainfall, with the NAO leading by $2-4$ years.

\section{Discussion and conclusions}

In the present study, the reconstructed NAO and the Monsoon Asian Drought Atlas, together with two sets of 600-year integrations with the BCM Version 2, were used to investigate the impact of the natural external forcing factors on the inter-decadal variation of the ISM rainfall, the winter NAO, and their relationship. The results suggest that the natural external forcing factors, particularly the 
volcanic eruptions, can influence the ISM rainfall by changing the Indian Ocean SST and can also induce positive phase NAO by increasing the pole-to-equator temperature gradient.

Previous studies have shown the substantial role of intensified solar activity in enhancing ISM rainfall on interdecadal timescale (e.g., Agnihotri et al. 2002; Bhattacharyya and Narasimha 2005; Gupta et al. 2005). In particular, the solar influence on monsoon activity is not through the changes of tropospheric radiation but through the modulation of upwelling in the equatorial troposphere, which originates from the stratosphere, and produces a northsouth seesaw of convective activity over the Indian Ocean (Kodera 2004). The previous studies have therefore neglected the possibility of the Indian Ocean SST in bridging the relationship between solar activity and ISM rainfall. In contrast, White et al. (1997) found that a basinaverage SST across the Indian Ocean is well correlated with the solar irradiance in two different datasets. Furthermore, they found that the TSI variations are greatest in the equatorial and tropical regions and attributed that to the incoming short-wave radiation at the top of the atmosphere. We did not find a significant relationship between the TSI and the ISM rainfall in our study. Instead, using both the reconstructed data and the simulations, we have shown that the volcanic eruptions can increase the ISM rainfall by reducing the Indian Ocean SST since the cooler (warmer) Indian Ocean SST tends to generate a lower-level divergence (convergence) and therefore strengthens (weakens) the ISM (e.g., Krishnamurthy and Goswami 2000; Kucharski et al. 2006). Our result indicates that the Indian Ocean SST decreases significantly by $0.15-0.25{ }^{\circ} \mathrm{C}$ 2-3 years after large volcanic eruptions, which is consistent with earlier studies (Robock 2002; Santer et al. 2003; D'Arrigo et al. 2008).

Previous studies have suggested either an inverse or a positive relationship between the winter NAO and the ISM rainfall on inter-decadal timescale (e.g., Dugam et al. 1997; Goswami et al. 2006). We did not find a significant correlation between the NAO and the ISM rainfall in CTL600, in agreement with previous studies about the impact of the Atlantic multi-decadal SST warmth on the ISM rainfall ( $\mathrm{Li}$ et al. 2008; Wang et al. 2009). However, a significant correlation has been found in EXT600 with the NAO leading the ISM rainfall by $2-4$ years, which is consistent with that revealed from the reconstructed NAO and PDSI from the MADA. In addition, the TEFI is significantly negatively correlated with the winter NAO and the ISM rainfall, with the TEFI leading the NAO and the ISM rainfall by 1 year and $3-5$ years, respectively. This implies a possible impact of natural external forcing factors on the statistical relationship between the NAO and ISM rainfall.
It should be mentioned that our results presented here cannot rule out that there is a strengthened destructive dynamical coupling between the NAO and the ISM as a consequence of natural external forcing factors. According to the mechanism described by Bader and Latif (2005), the post-eruption cooling of the surface tropical Indian Ocean would destructively feed back on the volcanically-induced positive phase of the NAO.

To summarize, we have shown that:

1. Natural external forcing factors did not lead to significant changes in the simulated seasonality of the ISM rainfall over the past 600 years;

2. Volcanic eruptions typically led to strengthened ISM circulation and ISM rainfall at the 3rd year after volcanic eruptions;

3. Natural external forcing factors, by affecting both the Indian Ocean SST and the winter NAO, could likely produce a stronger statistical but not causal relationship between the winter NAO and the ISM rainfall on inter-decadal timescale.

Acknowledgments The authors are grateful to the anonymous reviewers for their constructive comments which greatly improved the manuscript. This work was supported by the strategic Priority Research Program (XDA05110203) of the Chinese Academy of Sciences, and Research Council of Norway through the BlueArc, the India-Clim and the DecCen projects. The authors are also grateful to Dr. Odd Helge Otterå for model output.

Open Access This article is distributed under the terms of the Creative Commons Attribution License which permits any use, distribution, and reproduction in any medium, provided the original author(s) and the source are credited.

\section{References}

Agnihotri R, Dutta K, Bhushan R, Somayajulu B (2002) Evidence for solar forcing on the Indian monsoon during the last millennium. Earth Planet Sci Lett 198:521-527

Allan R, Ansell T (2006) A new globally complete monthly historical gridded mean sea level pressure dataset (HadSLP2): 1850-2004. J Clim 19(22):5816-5842

Bader J, Latif M (2005) North Atlantic Oscillation response to anomalous Indian Ocean SST in a coupled GCM. J Clim 18(24):5382-5389

Bhattacharyya S, Narasimha R (2005) Possible association between Indian monsoon rainfall and solar activity. Geophys Res Lett 32(5):L05813

Bleck R, Rooth C, Hu D, Smith LT (1992) Salinity-driven thermocline transients in a wind-and thermohaline-forced isopycnic coordinate model of the North Atlantic. J Phys Oceanogr 22:1486

Butterworth S (1930) On the theory of filter amplifiers. Exp Wirel Eng 7:536-541

Chang C, Harr P, Ju J (2001) Possible roles of Atlantic circulations on the weakening Indian monsoon rainfall-ENSO relationship. J Clim 14(11):2376-2380 
Cook ER, D'Arrigo RD, Mann ME (2002) A well-verified, multiproxy reconstruction of the winter North Atlantic Oscillation Index since AD 1400. J Clim 15(13):1754-1764

Cook ER, Anchukaitis KJ, Buckley BM, D’Arrigo RD, Jacoby GC, Wright WE (2010) Asian monsoon failure and mega drought during the last millennium. Science 328(5977):486

Crowley TJ (2000) Causes of climate change over the past 1000 years. Science 289(5477):270

Crowley TJ, Baum SK, Kim KY, Hegerl GC, Hyde WT (2003) Modeling ocean heat content changes during the last millennium. Geophys Res Lett 30(18):1932

D'Arrigo R, Wilson R, Tudhope A (2008) The impact of volcanic forcing on tropical temperatures during the past four centuries. Nat Geosci 2(1):51-56

Déqué M, Dreveton C, Braun A, Cariolle D (1994) The ARPEGE/IFS atmosphere model: a contribution to the French community climate modelling. Clim Dyn 10(4):249-266

Dugam S, Kakade S, Verma R (1997) Interannual and long-term variability in the North Atlantic Oscillation and Indian summer monsoon rainfall. Theor Appl Climatol 58(1):21-29

Fang K, Gou X, Chen F, Li J, D’Arrigo R, Cook E, Yang T, Davi N (2010) Reconstructed droughts for the southeastern Tibetan Plateau over the past 568 years and its linkages to the Pacific and Atlantic Ocean climate variability. Clim Dyn 35(4):577-585

Fleitmann D, Burns SJ, Mudelsee M, Neff U, Kramers J, Mangini A, Matter A (2003) Holocene forcing of the Indian monsoon recorded in a stalagmite from southern Oman. Science 300(5626):1737-1739

Free M, Robock A (1999) Global warming in the context of the Little Ice Age. J Geophys Res 104:19057-19070

Ganguly D, Rasch PJ, Wang HL, Yoon JH (2012) Fast and slow responses of the South Asian monsoon system to anthropogenic aerosols. Geophys Res Lett 39(18):L18804. doi:10.1029/ 2012gl053043

Gómez-Navarro JJ, Zorita E (2013) Atmospheric annular modes in simulations over the past millennium: no long-term response to external forcing. Geophys Res Lett 40:3232-3236

Gong DY, Yang J, Kim SJ, Gao Y, Guo D, Zhou T, Hu M (2011) Spring Arctic Oscillation-East Asian summer monsoon connection through circulation changes over the western North Pacific. Clim Dyn 37(11):2199-2216

Goswami B, Madhusoodanan M, Neema C, Sengupta D (2006) A physical mechanism for North Atlantic SST influence on the Indian summer monsoon. Geophys Res Lett 33:L02706

Graf HF, Kirchner I, Robock A, Schult I (1993) Pinatubo eruption winter climate effects: model versus observations. Clim Dyn 9(2):81-93

Gupta AK, Das M, Anderson DM (2005) Solar influence on the Indian summer monsoon during the Holocene. Geophys Res Lett 32(17):L17703

Haurwitz MW, Brier GW (1981) A critique of the superposed epoch analysis method: its application to solar-weather relations. Mon Weather Rev 109(10):2074-2079

Hope ACA (1968) A simplified Monte Carlo significance test procedure. J R Stat Soc Ser B 30:582-598

Howard R, Labonte B (1980) The Sun is observed to be a torsional oscillator with a period of 11 years. Astrophys J Lett 239:L33L36

Hurrell JW (1995) Decadal trends in the North Atlantic Oscillation: regional temperatures and precipitation. Science 269(5224): 675-679

Kalnay E, Kanamitsu M, Kistler R, Collins W, Deaven D, Gandin L, Iredell M, Saha S, White G, Woollen J (1996) The NCEP/NCAR 40-year reanalysis project. Bull Am Meteor Soc 77(3):437-471

Kodera K (2004) Solar influence on the Indian Ocean Monsoon through dynamical processes. Geophys Res Lett 31:L24209
Krishnamurthy V, Goswami B (2000) Indian monsoon-ENSO relationship on interdecadal timescale. J Clim 13(3):579-595

Kucharski F, Molteni F, Yoo J (2006) SST forcing of decadal Indian monsoon rainfall variability. Geophys Res Lett 33(3):L03709

Lau KM, Kim KM (2006) Observational relationships between aerosol and Asian monsoon rainfall, and circulation. Geophys Res Lett 33(21):L21810. doi:10.1029/2006gl027546

Lau K, Kim K, Yang S (2000) Dynamical and boundary forcing characteristics of regional components of the Asian summer monsoon. J Clim 13(14):2461-2482

Lau K, Kim M, Kim K (2006) Asian summer monsoon anomalies induced by aerosol direct forcing: the role of the Tibetan Plateau. Clim Dyn 26(7):855-864

Lehner F, Raible CC, Stocker TF (2012) Testing the robustness of a precipitation proxy-based North Atlantic Oscillation reconstruction. Quat Sci Rev 45:85-94

Li S, Perlwitz J, Quan X, Hoerling M (2008) Modelling the influence of North Atlantic multidecadal warmth on the Indian summer rainfall. Geophys Res Lett 35(5):L05804

Luo FF, Li SL, Furevik T (2011) The connection between the Atlantic Multidecadal Oscillation and the Indian Summer Monsoon in Bergen Climate Model Version 2.0. J Geophys Res 116:D19117. doi:10.1029/2011JD015848

Luterbacher J, Xoplaki E, Dietrich D, Rickli R, Jacobeit J, Beck C, Gyalistras D, Schmutz C, Wanner H (2002) Reconstruction of sea level pressure fields over the Eastern North Atlantic and Europe back to 1500 . Clim Dyn 18(7):545-561

Meehl GA, Arblaster JM, Collins WD (2008) Effects of black carbon aerosols on the Indian monsoon. J Clim 21(12):2869-2882

Mooley DA, Parthasarathy B (1982) Fluctuations in the deficiency of the summer monsoon over India, and their effect on economy. Arch Meteorol Geophys Bioklimatol Ser B 30(4):383-398

Mooley DA, Parthasarathy B, Sontakke NA, Munot AA (1981) Annual rain-water over India, its variability and impact on the economy. J Climatol 1(2):167-186

Mursula K, Usoskin I, Kovaltsov G (2001) Persistent 22-year cycle in sunspot activity: evidence for a relic solar magnetic field. Solar Phys 198(1):51-56

Otterå OH, Bentsen M, Bethke I, Kvamst NG (2009) Simulated preindustrial climate in Bergen climate model (version 2): model description and large-scale circulation features. Geosci Model Dev 2:197-212

Otterå OH, Bentsen M, Drange H, Suo L (2010) External forcing as a metronome for Atlantic multidecadal variability. Nature Geosci 3:688-694

Ramachandran S, Ramaswamy V, Stenchikov GL, Robock A (2000) Radiative impact of the Mount Pinatubo volcanic eruption: lower stratospheric response. J Geophys Res 105(D19):24409-24429

Ramanathan V, Chung C, Kim D, Bettge T, Buja L, Kiehl J, Washington W, Fu Q, Sikka D, Wild M (2005) Atmospheric brown clouds: impacts on South Asian climate and hydrological cycle. Proc Natl Acad Sci USA 102(15):5326-5333

Ramesh Kumar MR, Shenoi SSC, Schluessel P (1999) On the role of the cross equatorial flow on summer monsoon rainfall over India using NCEP/NCAR Reanalysis Data. Meteorol Atmos Phys 70(3):201-213

Robock A (2002) The climatic aftermath. Science 295(5558):1242-1244

Salas-Melia D (2002) A global coupled sea ice-ocean model. Ocean Model 4(2):137-172

Santer BD, Wehner MF, Wigley T, Sausen R, Meehl G, Taylor K, Ammann C, Arblaster J, Washington W, Boyle J (2003) Contributions of anthropogenic and natural forcing to recent tropopause height changes. Science 301(5632):479-483

Shindell DT, Schmidt GA, Mann ME, Rind D, Waple A (2001a) Solar forcing of regional climate change during the maunder minimum. Science 294(5549):2149-2152 
Shindell DT, Schmidt GA, Miller RL, Rind D (2001b) Northern hemisphere winter climate response to greenhouse gas, ozone, solar, and volcanic forcing. J Geophys Res 106(D7):7193-7210

Shindell DT, Schmidt GA, Miller RL, Mann ME (2003) Volcanic and solar forcing of climate change during the preindustrial era. J Clim 16(24):4094-4107

Shukla J (1975) Effect of Arabian sea-surface temperature anomaly on Indian summer monsoon: a numerical experiment with the GFDL model. J Atmos Sci 32:503-511

Singh J, Yadav RR, Wilmking M (2009) A 694-year tree-ring based rainfall reconstruction from Himachal Pradesh, India. Clim Dyn 33(7):1149-1158

Stenchikov GL, Kirchner I, Robock A, Graf HF, Antuña JC, Grainger R, Lambert A, Thomason L (1998) Radiative forcing from the 1991 Mount Pinatubo volcanic eruption. J Geophys Res 103(D12):13837-13857

Stenchikov G, Robock A, Ramaswamy V, Schwarzkopf MD, Hamilton K, Ramachandran S (2002) Arctic Oscillation response to the 1991 Mount Pinatubo eruption: effects of volcanic aerosols and ozone depletion. J Geophys Res 107(D24):4803

Swingedouw D, Terray L, Cassou C, Voldoire A, Salas-Melia D, Servonnat J (2011) Natural forcing of climate during the last millennium: fingerprint of solar variability. Clim Dyn 36(7): 1349-1364

Trouet V, Esper J, Graham NE, Baker A, Scourse JD, Frank DC (2009) Persistent positive North Atlantic Oscillation mode dominated the medieval climate anomaly. Science 324(5923):78-80

Wallace JM, Gutzler DS (1981) Teleconnections in the geopotential height field during the Northern Hemisphere winter. Mon Weather Rev 812:17-43
Wang Y, Cheng H, Edwards RL, He Y, Kong X, An Z, Wu J, Kelly MJ, Dykoski CA, Li X (2005) The Holocene Asian monsoon: links to solar changes and North Atlantic climate. Science 308(5723):854-857

Wang Y, Li S, Luo D (2009) Seasonal response of Asian monsoonal climate to the Atlantic Multidecadal Oscillation. J Geophys Res 114(D2):D02112

Wang T, Ottera OH, Gao YQ, Wang HJ (2012) The response of the North Pacific Decadal variability to strong tropical volcanic eruptions. Clim Dyn 39(12):2917-2936. doi:10.1007/s00382012-1373-5

Weare BC (1979) A statistical study of the relationships between ocean surface temperatures and the Indian monsoon. J Atmos Sci 36:2279-2291

White WB, Lean J, Cayan DR, Dettinger MD (1997) Response of global upper ocean temperature to changing solar irradiance. J Geophys Res 102(C3):3255-3266

Zanchettin D, Timmreck C, Graf H-F, Rubino A, Lorenz S, Lohmann K, Krüger K, Jungclaus J (2012) Bi-decadal variability excited in the coupled ocean-atmosphere system by strong tropical volcanic eruptions. Clim Dyn 39(1-2):419-444

Zanchettin D, Rubino A, Matei D, Bothe O, Jungclaus JH (2013a) Multidecadal-to-centennial SST variability in the MPI-ESM simulation ensemble for the last millennium. Clim Dyn 40: $1301-1318$

Zanchettin D, Timmreck C, Bothe O, Lorenz SJ, Hegerl G, Graf HF, Luterbacher J, Jungclaus JH (2013b) Delayed winter warming: a robust decadal response to strong tropical volcanic eruptions? Geophys Res Lett 40:204-209 